\title{
Multidisciplinary Team Meetings-a Venue to Improve Team Engagement and Quality in Resident Continuity Clinic
}

\author{
Amalia Lyons, $M D^{1}$, Rebekah J. Walker, $P h D^{1,2}$, Heather L. Prigmore, $M P H^{1,2}$, and \\ Marty Muntz, MD ${ }^{1,3}$
}

'Division of General Internal Medicine, Department of Medicine, Froedtert \& The Medical College of Wisconsin, Milwaukee, WI, USA; ${ }^{2}$ Center for Advancing Population Science, Medical College of Wisconsin, Milwaukee, WI, USA; ${ }^{3}$ Kern Institute for the Transformation of Medical Education, Medical College of Wisconsin, Milwaukee, WI, USA.

J Gen Intern Med 34(10):2001-2

DOI: $10.1007 / \mathrm{s} 11606-019-05084-6$

(c) Society of General Internal Medicine 2019

\section{BACKGROUND}

Suboptimal continuity, complex patients, and poor resident integration into the Patient-Centered Medical Home (PCMH) structure contribute to limited resident satisfaction with resident continuity clinic (RCC). The Society of General Internal Medicine has recognized the need for resident PCMH training and developed PCMH entrustable professional activities. ${ }^{1}$

Studies looking at integrating residents into the PCMH more fully to improve the RCC experience have shown mixed results. Hochman et al. implemented PCMH concepts of care coordination, enhanced access, and team-based care into RCC. $^{2}$ A pre- and post-survey showed improved resident and patient satisfaction with clinic, with a modestly (but non-significant) increase interest in primary care. Conversely, passive learning and didactics were insufficient to prepare residents for practice. ${ }^{3}$ We embedded a multidisciplinary team meeting within RCC to improve residents' knowledge of $\mathrm{PCMH}$ and satisfaction with RCC.

\section{METHODS}

This study was designed with the purpose of investigating team function and satisfaction with the multidisciplinary team meetings in our RCC. The data was collected through surveys at baseline and 12 months post intervention. Team function was measured using a validated scale of fifteen questions. ${ }^{4}$ All questions had ordinal responses of rarely, sometimes, and usually: assigned values 1,2 , and 3 , respectively. The fifteen questions were then divided into five categories, each consisting of three questions that were summed to obtain the overall team function in each category. Satisfaction scores were measured using eleven questions for residents and twelve for attending physicians based on questions used in prior studies. ${ }^{2}$ The satisfaction questions revolved around support in clinic, delivery of care, and general experience; a composite score aggregated all responses.

Statistical analyses were conducted using Stata Version 13 (StataCorp; College Station, TX). Outcomes for all measures

Published online June 13, 2019 of team function and satisfaction were calculated for residents and attending physicians. $T$ tests for continuous outcomes and Fisher's exact test for categorical outcomes were compared at baseline and post intervention. Significance was evaluated at the 0.10 level.

\section{RESULTS}

There were 24 resident (15 pre, 9 post) and 17 attending physician (10 pre, 7 post) responses. Table 1 displays the mean and standard deviation of each team function category pre and post intervention. Team function levels decreased for residents and increased for attending physicians; one measure remained the same in each group. Table 2 shows the percentage of participants that were satisfied with each measure for the pre- and post-survey. Fifty-five percent of satisfaction scores decreased from the initial survey results for residents, but only $27 \%$ were below the reference value from Hochman et al.'s study. Seventy-five percent of attending physician satisfaction scores increased and all had values above the reference. Resident's team function measure of inattention to results $(p=$ $0.08)$ and attending physicians' absence of trust $(p=0.08)$ were the only two outcomes that showed a statistically significant difference after intervention.

Table 1 Dysfunction Scores

\begin{tabular}{|c|c|c|c|c|}
\hline & $\begin{array}{l}\text { Mean } \pm \\
\text { std (pre) }\end{array}$ & $\begin{array}{l}\text { Mean } \pm \\
\text { std (post) }\end{array}$ & $\begin{array}{l}\text { Mean } \pm \\
\text { std (pre) }\end{array}$ & $\begin{array}{l}\text { Mean } \pm \\
\text { std (post) }\end{array}$ \\
\hline & \multicolumn{2}{|l|}{ Residents } & \multicolumn{2}{|c|}{ Attending physicians } \\
\hline Absence of trust & $7.1 \pm 1.8$ & $7.1 \pm 1.2$ & $5.9 \pm 1.8$ & $7.3 \pm 0.8$ \\
\hline Fear of conflict & $8.1 \pm 1.2$ & $7.7 \pm 1.7$ & $6.9 \pm 2.2$ & $6.9 \pm 1.2$ \\
\hline $\begin{array}{l}\text { Lack of } \\
\text { commitment }\end{array}$ & $7.0 \pm 1.8$ & $6.4 \pm 1.3$ & $6.0 \pm 2.1$ & $6.6 \pm 1.1$ \\
\hline $\begin{array}{l}\text { Avoidance of } \\
\text { accountability }\end{array}$ & $6.3 \pm 1.1$ & $5.7 \pm 1.2$ & $5.8 \pm 1.9$ & $6.4 \pm 1.5$ \\
\hline $\begin{array}{l}\text { Inattention to } \\
\text { results }\end{array}$ & $6.6 \pm 1.6$ & $5.7 \pm 1.1$ & $6.3 \pm 1.4$ & $6.6 \pm 1.0$ \\
\hline
\end{tabular}

$p$ value $<0.10$; scores of $8-9$ indicate unlikely a problem, scores of 6-7 indicate could be a problem, and scores of 3-5 indicate needs to be addressed 
Table 2 Resident and Attending Satisfaction

\begin{tabular}{llll}
\hline \hline Characteristic & \% satisfied (pre) & \% satisfied (post) & Reference: Hochman baseline \\
\hline Residents & & & $56 \%$ \\
Adequate nursing support & $60 \%$ & $89 \%$ & $26 \%$ \\
Adequate case management & $33 \%$ & $33 \%$ & $53 \%$ \\
Adequate overall support & $73 \%$ & $78 \%$ & $23 \%$ \\
Clinic structure supports continuity of care & $66 \%$ & $63 \%$ & - \\
Feel like the primary care physician for patients & $60 \%$ & $78 \%$ & $58 \%$ \\
Patients see me as primary care physician & $50 \%$ & $56 \%$ & $16 \%$ \\
Confidence in post-residency practice in GIM & $60 \%$ & $44 \%$ & $72 \%$ \\
Interest in primary care career & $27 \%$ & $11 \%$ & - \\
More respect for primary care physicians & $80 \%$ & $78 \%$ & $39 \%$ \\
Overall rating of clinic experience & $47 \%$ & $38 \%$ & $56 \%$ \\
Understand basic concept of PCMH & $47 \%$ & $44 \%$ & $26 \%$ \\
Composite score* & $55 \%$ & $55 \%$ & $53 \%$ \\
Attending physicians & $67 \%$ & $71 \%$ & $23 \%$ \\
Adequate nursing support & $33 \%$ & $43 \%$ & - \\
Adequate case management & $50 \%$ & $86 \%$ & - \\
Adequate overall support & $44 \%$ & $57 \%$ & - \\
Clinic structure supports continuity of care & $67 \%$ & $71 \%$ & - \\
My residents take ownership of patients & $100 \%$ & $86 \%$ & - \\
Patients see resident as PCP & $44 \%$ & $57 \%$ & - \\
My residents understand basic PCMH concepts & $38 \%$ & $71 \%$ & - \\
Team meetings improve residents relation to team & $38 \%$ & $43 \%$ & - \\
Team meetings improve residents care of patients & $25 \%$ & $43 \%$ & $39 \%$ \\
Team meetings improve care my patients receive & $75 \%$ & $57 \%$ & $14 \%$ \\
Team meetings improve my relation to team & $50 \%$ & $58 \%$ & \\
Team meetings improve my relation with patients & $45 \%$ & & \\
Composite score* & & & \\
\hline
\end{tabular}

$p$ value $<0.10$

*Composite score represents the percentage of all survey questions receiving favorable response

\section{DISCUSSION}

We have shown that a multidisciplinary team meeting improves residents' knowledge of PCMH. This was reflected in how more residents felt like the primary care provider, had adequate nursing support, and had adequate overall support. However, residents also had less confidence in post-residency practice in GIM and fewer had interest in a primary care career. We suspect residents were more knowledgeable than perceived regarding PCMH concepts and their patient population, including the barriers and challenges to providing primary care, which resulted in decreased confidence and interest in primary care. Additionally, residents likely perceived they understood PCMH before the intervention but after the intervention reflects more accurately their understanding and knowledge of the PCMH concepts. Interestingly, faculty members tended to have a more positive response on the satisfaction survey after the intervention, likely from the perception that residents were more actively involved in the $\mathrm{PCMH}$.

Improving both resident satisfaction with RCC and knowledge of and integration into a PCMH is a complex process. Multidisciplinary team meetings are just one strategy with potential application, but more work is needed to improve curriculum around $\mathrm{PCMH}$, incorporate all team members into a cohesive unit, and improve faculty development. In addition, residents must be equipped with adequate support and resources to help them overcome barriers and challenges to provide excellent care for their patients.

Corresponding Author: Amalia Lyons, MD; Division of General Internal Medicine, Department of Medicine Froedtert \& The Medical College of Wisconsin, Milwaukee, WI, USA (e-mail: ajlyons@mcw.edu).

\section{Compliance with Ethical Standards:}

Conflict of Interest: The authors declare that they do not have a conflict of interest.

\section{REFERENCES}

1. Chang A, Bowen JL, Buranosky RA, et al. Transforming primary care training-patient centered medical home entrustable professional activities for internal medicine residents. J Gen Intern Med. 2012;28(6):801809.

2. Hochman ME, Asch S, Jibilian A, et al. Patient Centered Medical Home intervention at an Internal Medicine Resident Safety Net Clinic. JAMA Intern Med. 2013;173(18):1694-1701.

3. Rayess EL F, Goldman R, Furey C, Goldberg AR, Chandran R, Anandarajah G. Patient centered medical home knowledge and attitudes of residents and faculty: certification is just the first step. J Grad Med Educ. 2015;7(4):580-588.

4. Lencioni. The five dysfunctions of a team: A leadership Fable. New York: Wiley and Sons; 2011;192-194.

Publisher's Note Springer Nature remains neutral with regard to jurisdictional claims in published maps and institutional affiliations. 